\title{
Dissolution of metal precipitates in multicrystalline silicon during annealing and the protective effect of phosphorus emitters
}

\author{
J. Tan, D. Macdonald, N. Bennett, D. Kong, and A. Cuevas \\ Department of Engineering, College of Engineering and Computer Science, Australian National University, \\ Canberra ACT 0200, Australia \\ I. Romijn \\ ECN Solar Energy, P.O. Box 1, NL-1755 ZG Petten, The Netherlands
}

(Received 4 June 2006; accepted 3 July 2007; published online 24 July 2007)

\begin{abstract}
The degradation of the carrier lifetime in multicrystalline silicon due to the dissolution of metal precipitates during high temperature annealing is well known. This letter presents evidence indicating that the presence of phosphorus emitters during annealing can help reduce this recontamination. Part of the degradation observed is due to increased interstitial iron concentrations caused by the dissolution of iron precipitates during annealing. However, dissolution of other metals also seems to contribute to the reduced carrier lifetimes observed. (C) 2007 American Institute of Physics. [DOI: 10.1063/1.2766664]
\end{abstract}

Multicrystalline silicon (mc-Si) wafers for solar cells are known to contain significant quantities of metallic impurities. ${ }^{1,2}$ The chemical state and spatial distribution of these metals in silicon can be influenced by annealing. This letter examines the role of metal precipitates inherent to $\mathrm{mc}-\mathrm{Si}$ and the effects that annealing in the presence or absence of phosphorus emitters has on the electronic properties of mc-Si wafers.

Thirteen wafers from each of six evenly spaced regions of a $125 \times 125 \mathrm{~mm}^{2}$ p-type $1 \Omega \mathrm{cm}$ (nominal) mc-Si brick were selected. One wafer from each region was alkaline then acid etched, before being passivated and set aside as an "asgrown" control. The remaining 12 wafers were alkaline etched and RCA cleaned before a 30 min double sided phosphorus diffusion resulting in a sheet resistance of $60 \Omega \backslash \square$. Once the $\mathrm{POCl}_{3}$ diffusion source was turned off, the furnace was slowly cooled to $600{ }^{\circ} \mathrm{C}$ (approximately $1 \mathrm{~h}$ ). Samples were then kept in a $\mathrm{N}_{2}$ ambient at $600{ }^{\circ} \mathrm{C}$ for $5 \mathrm{~h}$. This extended diffusion tail was designed to allow maximum gettering of interstitial iron, while minimizing any "drive in" of the phosphorus diffusion., ${ }^{3,4}$ Seven wafers from each section were then stripped of their $n^{+}$emitters by acid etch. All samples then received a double sided plasma enhanced chemical vapor deposition silicon nitride $(\mathrm{SiN})$ coating, deposited with a Roth and Rau SiNA reactor. The SiN film has a refractive index of 2.1 and $\mathrm{Si}-\mathrm{N}$ bond density of $1.3 \times 10^{23}$ atoms $/ \mathrm{cm}^{3}$.

Wafers stripped of $n^{+}$emitters were then characterized with area averaged $\left(\sim 600 \mathrm{~mm}^{2}\right)$ quasisteady-state photoconductance $^{6}$ at nine points across each sample $(\Delta n=1$ $\left.\times 10^{15} \mathrm{~cm}^{-3}\right)$. Approximately $\frac{1}{3}$ of the surface area of each wafer was covered by these measurements. Postgettering effective lifetime $\left(\tau_{\text {eff }}\right)$ and interstitial iron concentration $\left[\mathrm{Fe}_{i}\right]$ (Refs. 7-9) at each section of the brick were determined from the average of these measurements. Some of the samples were then "fired" in a rapid thermal processing (RTP) furnace using five conditions: three short anneals $\left(700,800\right.$, and $900{ }^{\circ} \mathrm{C}$ with $3 \mathrm{~s}$ dwell time) and two longer anneals $\left(800{ }^{\circ} \mathrm{C}\right.$ with $30 \mathrm{~s}$ and $300 \mathrm{~s}$ dwell time). The annealed SiN films were removed by dilute HF. Wafers which previously retained their emitters were acid etched and all samples received a fresh $\mathrm{SiN}$ to suppress surface recombination. All wafers were then recharacterized.

$1 \Omega \mathrm{cm}$ float zone wafers coated in the same $\mathrm{SiN}$ were also included in the experiment to evaluate possible furnace contamination. A very minor increase in $\left[\mathrm{Fe}_{i}\right]$ was detected in these samples $\left(1 \times 10^{10} \rightarrow 5 \times 10^{10}\right.$ atoms $\left./ \mathrm{cm}^{3}\right)$ after a $300 \mathrm{~s}$ anneal at $800{ }^{\circ} \mathrm{C}$, reflecting the efficacy of the SiN film as a diffusion barrier to external contamination. Therefore any significant increases in $\left[\mathrm{Fe}_{i}\right]$ above this level in the mc-Si wafers after annealing must be due to a contamination source internal to the wafer.

Figure 1 displays the $\tau_{\mathrm{eff}}$ and $\left[\mathrm{Fe}_{i}\right]$ of as-cut and gettered wafers across the mc-Si brick. Increased $\tau_{\text {eff }}$ and reduced $\left[\mathrm{Fe}_{i}\right]$ were observed across all regions of the brick after gettering. Most of the $\left[\mathrm{Fe}_{i}\right]$ data after gettering in Fig. 1(b) are close to the detection limits of this technique $\left(\sim 10^{10}\right.$ atoms $\left./ \mathrm{cm}^{3}\right)$ and are a display of the extended diffusion efficacy at gettering fast diffusing impurities.

After "firing," a significant divergence between the samples annealed with and without phosphorus emitters emerges [see Fig. 2(a)]. Many researchers have reported improved $\tau_{\text {eff }}$ after annealing $\mathrm{SiN}$ coated mc-Si wafers, in the presence of a phosphorus emitter, as observed in Fig. 2(a). This is due to the passivation of grain boundaries, lattice defects, and other impurities by $\mathrm{SiN}$ induced hydrogenation. ${ }^{10,11}$ However, the degradation of $\tau_{\text {eff }}$ when the wa-
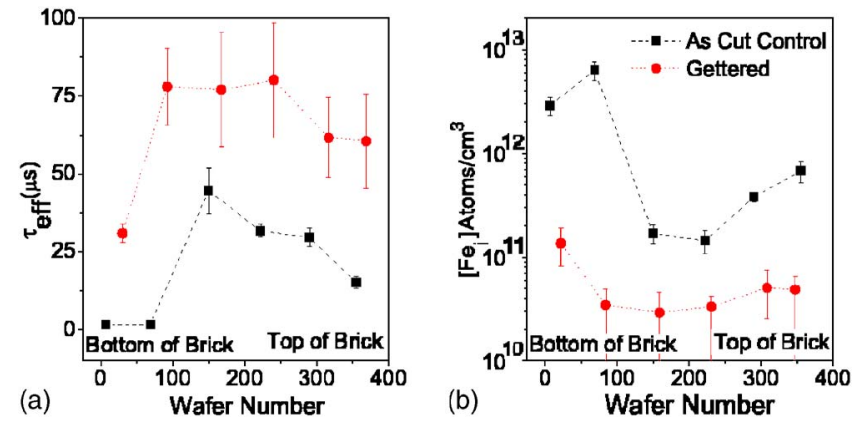

FIG. 1. (Color online) (a) Effective lifetime and (b) interstitial iron concentrations as a function of wafer number. Error bars are the standard deviation of results. Negative error bars approaching zero indicate the detection limit. 

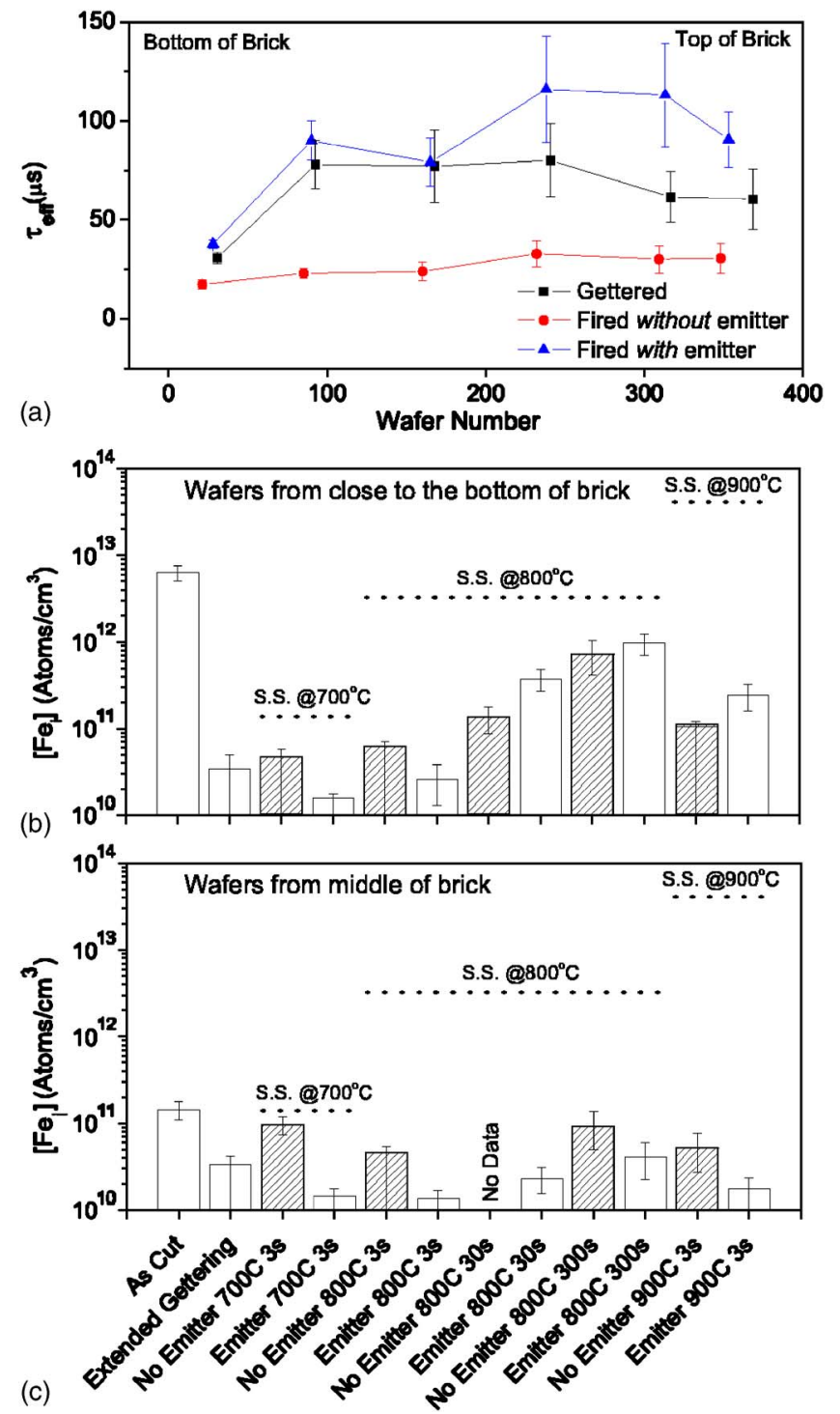

FIG. 2. (Color online) (a) Effective lifetime of samples annealed with and without emitters at $800{ }^{\circ} \mathrm{C}$ for $3 \mathrm{~s}$ across the whole brick. Interstitial iron concentration of wafers sourced from (b) close to the bottom of the brick and (c) the middle of the brick after various annealing treatments. The dotted lines represent the solid solubility limits of iron at the prescribed annealing temperatures. The error bars represent the standard deviation of results. Negative error bars approaching zero indicate the detection limit.

fer is annealed with $\mathrm{SiN}$ but without a phosphorus emitter has not previously been observed, though other researchers have conducted similar experiments. ${ }^{12,13}$ In the absence of an emitter, degraded $\tau_{\text {eff }}$ were observed for all annealing conditions across all sections of the brick. One of the possible causes of the reduced $\tau_{\text {eff }}$ is investigated in Figs. 2(b) and 2(c), which examines the $\left[\mathrm{Fe}_{i}\right]$ of wafers taken from close to the bottom [(b) wafer number 82-91] and middle [(c) wafers number 229-238] of the brick.

The $\left[\mathrm{Fe}_{i}\right]$ of as-grown wafers from close to the bottom and middle of the brick are similar to what has previously been reported. ${ }^{1,14}$ After gettering, the $\left[\mathrm{Fe}_{i}\right]$ of both sets of samples are essentially the same. Wafers sourced from lower in the brick [Fig. 2(b)], annealed without their emitters (striped bars), display an increased $\left[\mathrm{Fe}_{i}\right]$ compared to their gettered values. A clear correlation between increasing $\left[\mathrm{Fe}_{i}\right]$ and increasing thermal budget is found for these samples. Similar wafers annealed with their emitters (nonstriped bars) Downloaded 25 Jul 2007 to 150.203 .45 .136 . Redistribution subject
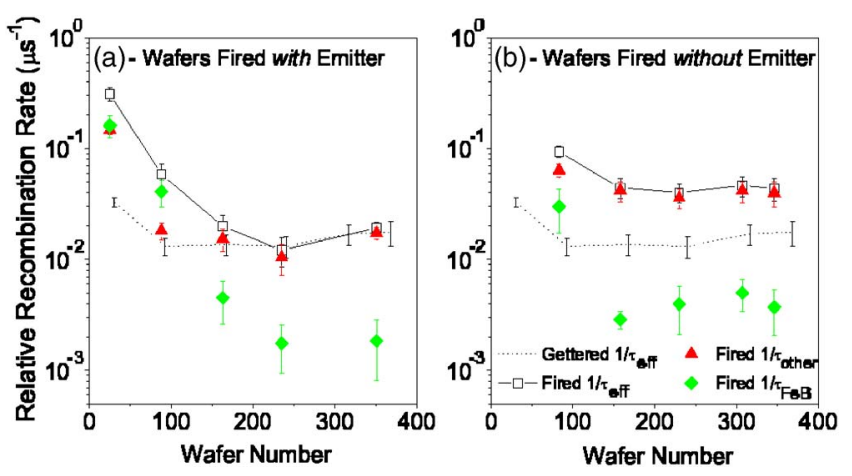

FIG. 3. (Color online) Components of the relative recombination rate for wafers annealed (a) with and (b) without emitters at $800{ }^{\circ} \mathrm{C}$ for $300 \mathrm{~s}$ across the whole brick.

at 700 and $800{ }^{\circ} \mathrm{C}$ for $3 \mathrm{~s}$ display no increase in $\left[\mathrm{Fe}_{i}\right]$. However, wafers annealed at $900{ }^{\circ} \mathrm{C}$ for $3 \mathrm{~s}$ and $800{ }^{\circ} \mathrm{C}$ for $300 \mathrm{~s}$, with and without emitters, produce similar $\left[\mathrm{Fe}_{i}\right]$ results. Wafers sourced from the middle of the brick [Fig. 2(c)], annealed without an emitter, also exhibit an increased $\left[\mathrm{Fe}_{i}\right]$. However, they show no obvious correlation between the increased $\left[\mathrm{Fe}_{i}\right]$ and annealing time or temperature. Wafers from the middle of the brick, annealed with their emitters, exhibit a low $\left[\mathrm{Fe}_{i}\right]$ for all annealing conditions.

The most likely cause of the increased $\left[\mathrm{Fe}_{i}\right]$ observed after annealing is the dissolution of iron precipitates during the anneal. ${ }^{2}$ High total Fe concentrations (including precipitated and interstitial iron) have been measured in directionally solidified mc-Si. Profiles of mc-Si bricks reveal that iron concentrations are higher at the bottom and top of the ingots. ${ }^{1}$ Typically, $<1 \%$ of the iron is in interstitial form, so the overwhelming majority is in a precipitated state. ${ }^{1}$ Using contaminated floating zone material, researchers ${ }^{15}$ have shown that $\beta-\mathrm{FeSi}_{2}$ is the preferred precipitate state at temperatures below $900{ }^{\circ} \mathrm{C}$, and that this precipitate is vulnerable to dissolution at temperatures above $760^{\circ} \mathrm{C}$. Therefore, dissolution of $\beta-\mathrm{FeSi}_{2}$ precipitates is the likely source of $\mathrm{Fe}_{i}$ we observe in the samples which register an increased $\left[\mathrm{Fe}_{i}\right]$ after annealing, resulting in $\left[\mathrm{Fe}_{i}\right]$ approaching the solubility limit, ${ }^{16}$ as shown in Fig. 2(b).

This explanation is consistent with our results, as samples annealed in Fig. 2(b) without an emitter at $700{ }^{\circ} \mathrm{C}$ resulted in the least repoisoning, while higher temperatures and longer annealing times allowed greater dissolution of $\beta$ - $\mathrm{FeSi}_{2}$ precipitates. The varying contaminant concentration across the brick (with a minimum in the middle of the brick) also explains why we observe higher $\left[\mathrm{Fe}_{i}\right]$ at lower regions of the brick after annealing, as this is where the highest concentration of precipitates lies. However, as a uniformly reduced $\tau_{\text {eff }}$ was observed across the length of the brick for wafers annealed without an emitter, and not only in regions of the brick which contain very high concentrations of $\mathrm{Fe}$ precipitates, other factors must also be behind the degradation observed.

The total recombination rate $(U)$ in a sample is proportional to the $\tau_{\text {eff }}^{-1}$, which can be broken into its components: $\tau_{\text {eff }}^{-1}=\tau_{\mathrm{FeB}}^{-1}+\tau_{\mathrm{other}}^{-1} \tau_{\mathrm{FeB}}^{-1}$ represents the rate of recombination due to iron-boron (FeB) pairs (which is the form that $\mathrm{Fe}_{i}$ takes before illumination). $\tau_{\text {other }}^{-1}$ represents the rate of recombination due to all other recombination channels. Figure 3 shows these components along the ingot length, for wafers o AIP license or copyright, see http://apl.aip.org/apl/copyright.jsp 
annealed with [Fig. 3(a)] and without [Fig. 3(b)] emitters at $800{ }^{\circ} \mathrm{C}$ for $300 \mathrm{~s}$. Due to the efficacy of the gettering process at removing $\mathrm{Fe}_{i}$ from the wafers, the $\tau_{\text {eff }}^{-1}$ of gettered wafers is completely dominated by $\tau_{\text {other }}^{-1}$. Though these two terms are the same in gettered wafers, $\tau_{\text {eff }}^{-1}$ has been used in Fig. 3 .

For the wafer from the very bottom of the brick in Fig. 3(a), $U$ is evenly split between $\tau_{\mathrm{FeB}}^{-1}$ and $\tau_{\text {other }}^{-1}$. As expected, dissolution of Fe precipitates has increased $\tau_{\mathrm{FeB}}^{-1}$ in this wafer. Interestingly though, $\tau_{\text {other }}^{-1}$ has also increased. Results from the next lowest section of the brick show that $\tau_{\mathrm{FeB}}^{-1}$ accounts for approximately $\frac{2}{3}$ of $U$ in a wafer annealed with an emitter [Fig. 3(a)]. In contrast, for a neighboring wafer annealed without an emitter [Fig. 3(b)], $\tau_{\text {other }}^{-1}$ accounts for approximately $\frac{2}{3}$ of $U$. In both cases, $\tau_{\mathrm{FeB}}^{-1}$ is essentially constant. This indicates that the presence of an emitter during high temperature annealing helps retard the degradation of $\tau_{\text {other }}^{-1}$, but is unable to stop $\tau_{\mathrm{FeB}}^{-1}$ increasing above the gettered value.

This hypothesis is supported by the remaining results of Figs. 3(a) and 3(b). For wafers sourced from the middle and top of the mc-Si brick, which were annealed with an emitter, Fig. 3(a) shows that $\tau_{\text {other }}^{-1}$ does not change from its gettered values. In comparison, $\tau_{\text {other }}^{-1}$ of wafers annealed without an emitter [Fig. 3(b)] have increased substantially above that of the gettered wafers. In both cases (annealed with or without an emitter), $\tau_{\text {other }}^{-1}$ dominates $U$ (often by an order of magnitude) for all wafers sourced from the middle/ top of the brick. This corresponds well with the low $\left[\mathrm{Fe}_{i}\right]$ displayed in Fig. 2(c), for annealed wafers from the middle of the ingot.

It is interesting to consider what mechanism enables the phosphorus emitters to reduce degradation of the $\tau_{\text {eff }}$, considering that the annealing times were too short for significant diffusion of impurities to gettering sites. Two techniques used in this experiment are known to improve the electronic properties of mc-Si: SiN induced hydrogenation and phosphorus gettering of metallic impurities.

Researchers have shown that defects at the surface of silicon wafers, like those caused by phosphorus diffusions, can improve the dissolution of molecular hydrogen, thereby improving its bulk passivation capabilities. ${ }^{17}$ The analysis of results from an experiment similar to this one, ${ }^{12}$ supports this theory. However, we believe that this hypothesis is not applicable to our results due to the high density of SiN film employed. Recently published work ${ }^{18}$ shows that hydrogen released from dense SiN films is in atomic and not molecular form. Hence, the passivation capability of the SiN used in this experiment should not have been compromised by the lack of a phosphorus diffusion during annealing.

Another possible mechanism which might explain the differences observed between wafers annealed with and without their emitters is "light enhanced gettering." 19 As the annealings were performed in an RTP furnace, which heats the samples predominately by visible radiation, the diffusion of dissolved metal impurities could be enhanced by the presence of additional electron-hole pairs. ${ }^{20}$ However, the intrinsic carrier concentration of silicon at $800{ }^{\circ} \mathrm{C}$ is $\sim 10^{18} \mathrm{~cm}^{-3},{ }^{21}$ which is probably much larger than the carrier concentration generated by the incident light. Therefore, it is unlikely that light enhanced gettering is the mechanism responsible for our results.

In this letter we have shown that precipitated contaminants, among them possibly $\beta$-FeSi ${ }_{2}$, can be dissolved back into the lattice during annealing. The presence of a phosphorus emitter during annealing, can prevent degradation of the $\tau_{\text {eff }}$, attributed to the dissolution of Fe and other metal precipitates, if a moderate to low thermal budget is employed. This is especially important in regions where high concentrations of precipitates are known to lie. However, the mechanism by which the phosphorus emitter provides protection is not understood.

The authors would like to acknowledge the Australian Research Council for funding this work and Bart Geerligs for his insightful suggestions.

${ }^{1}$ D. Macdonald, A. Cuevas, A. Kinomura, Y. Nakano, and L. Geerligs, J. Appl. Phys. 97, 033523 (2005).

${ }^{2}$ T. Buonassisi, A. Istratov, S. Peters, C. Ballif, J. Isenberg, S. Riepe, W. Warta, R. Schindler, G. Willeke, Z. Cai, L. Lai, and E. Weber, Appl. Phys. Lett. 87, 121918 (2005).

${ }^{3}$ J. Härkönen, V.-P. Lempinen, T. Juvonen, and J. Kylmäluoma, Sol. Energy Mater. Sol. Cells 73, 125 (2002).

${ }^{4}$ P. Manshanden and L. Geerligs, Sol. Energy Mater. Sol. Cells 90, 998 (2006).

${ }^{5}$ I. Romijn, W. Soppe, H. Rieffe, W. Sinke, and A. Weeber, Proceedings of the 15th Workshop on Crystalline Silicon Solar Cells and Modules: Materials and Processes (National Renewable Energy Laboratory, Vail, Colorado, 2005), pp. 85-92.

${ }^{6}$ R. A. Sinton and A. Cuevas, Appl. Phys. Lett. 69, 2510 (1996).

${ }^{7}$ G. Zoth and W. Bergholz, J. Appl. Phys. 67, 6764 (1990).

${ }^{8}$ D. Macdonald, L. Geerligs, and A. Azzizi, J. Appl. Phys. 95, 1021 (2004).

${ }^{9}$ D. Macdonald, T. Roth, P. Deenapanray, T. Trupke, and R. Bardos, Appl. Phys. Lett. 89, 142107 (2006).

${ }^{10}$ S. Martinuzzi, I. Perichaud, and F. Warchol, Sol. Energy Mater. Sol. Cells 80, 343 (2003).

${ }^{11}$ M. Rinio, M. Kaes, G. Hahn, and D. Borchert, Proceedings of the 21st European Photovoltaic and Solar Energy Conference, Dresden, Germany (WIP, Munich, Germany, 2006).

${ }^{12}$ J. Henze, C. Schmiga, J. Schmidt, and R. Hezel, Proceedings of the 19th European Photovoltaic and Solar Energy Conference, Paris France (WIP, Munich, Germany, 2004), pp. 907-910.

${ }^{13}$ A. Azzizi, L. Geerligs, and A. Burgers, Proceedings of the 3rd World Conference on Photovoltaic Energy Conversion, Osaka, Japan (WCPEC-3, Japan, 2003).

${ }^{14}$ R. Sinton, T. Mankad, S. Bowden, and N. Enjalbert, Proceedings of the 19th European Photovoltaic and Solar Energy Conference, Paris, France (WIP, Munich, Germany, 2004), pp. 520-523.

${ }^{15}$ D. A. Ramappa and W. B. Henley, J. Electrochem. Soc. 144, 4353 (1997).

${ }^{16} \mathrm{~K}$. Graff, Metal Impurities in Silicon-Device Fabrication, Springer Series in Material Science (Springer, Berlin, 1999), Vol. 24, 2nd ed., p. 22.

${ }^{17}$ S. K. Estreicher, J. L. Hastings, and P. A. Fedders, Phys. Rev. B 57, R12663 (1998).

${ }^{18}$ H. Dekkers, G. Beaucarne, M. Hiller, H. Charifi, and A. Slaoui, Appl. Phys. Lett. 89, 211914 (2006).

${ }^{19}$ B. Hartiti, A. Slaoui, M. Loghmarti, J. C. Mullet, and P. Siffert, Appl. Phys. Lett. 59, 3446 (1991).

${ }^{20}$ L. Kimberling and J. Benton, Physica B 116, 297 (1987).

${ }^{21}$ F. J. Morin and J. P. Maita, Phys. Rev. 96, 28 (1954). 